\title{
Article \\ Improving Safety Management through Analysis of Near-Miss Reports-A Tanker Ship Case Study
}

\author{
Nermin Hasanspahić ${ }^{1, *(D)}$, Srđan Vujičić ${ }^{1}$ (D) Miho Kristić ${ }^{1}$ and Mario Mandušić ${ }^{2}$ (I) \\ 1 Maritime Department, University of Dubrovnik, 20000 Dubrovnik, Croatia; srdjan.vujicic@unidu.hr (S.V.); \\ miho.kristic@unidu.hr (M.K.) \\ 2 Independent Researcher, 20000 Dubrovnik, Croatia; mario.mandusic1729@gmail.com \\ * Correspondence: nermin.hasanspahic@unidu.hr
}

check for updates

Citation: Hasanspahić, N.; Vujičić, S.; Kristić, M.; Mandušić, M. Improving Safety Management through Analysis of Near-Miss Reports-A Tanker Ship Case Study. Sustainability 2022, 14, 1094. https://doi.org/10.3390/ su14031094

Academic Editors: Mara Lombardi, Fatma El Zahraa Ashour,

Massimo Guarascio and

Mario Fargnoli

Received: 9 December 2021

Accepted: 17 January 2022

Published: 18 January 2022

Publisher's Note: MDPI stays neutral with regard to jurisdictional claims in published maps and institutional affiliations.

Copyright: (C) 2022 by the authors. Licensee MDPI, Basel, Switzerland. This article is an open access article distributed under the terms and conditions of the Creative Commons Attribution (CC BY) license (https:// creativecommons.org/licenses/by/ $4.0 /)$.

\begin{abstract}
A near-miss management system (NMMS) is a tool used for improving safety at sea if adequately implemented. Valuable knowledge to improve safety management might be gained by investigating and analysing reported events. Therefore, it is of the utmost importance to report each observed near-miss event. Because tankers are generally considered dangerous, but at the same time safe due to stringent requirements, near-miss reports and NMMS policy were collected from one oil tanker ship. Data were pre-processed and analysed. Variables used during analysis were near-miss type, risk level, ship position, and onboard location of near-miss occurrence. Analysis of policy and reports revealed that most near misses occurred on the deck area, but higher-risklevel events were reported in the engine room and navigating bridge. Housekeeping, equipment failure, use of personal protective equipment (PPE), and process-/procedure-related events were most common and generally related to lower risk levels. The most frequent corrective actions recorded were implementing safe working practices and PPE. In addition, higher-risk-level events were related to less effective corrective actions. Based on the findings, suggestions for improvements include promoting safe behaviour and adequate PPE usage through additional training, ensuring proper housekeeping, regular maintenance of shipboard equipment and spare parts management, and toolbox meetings and risk assessments that include conclusions of near-miss investigations and analysis.
\end{abstract}

Keywords: maritime safety; shipping; near miss; risk management; oil tanker

\section{Introduction}

Maritime transport plays an essential role in international trade and is considered a backbone of the global economy [1]. According to the UNCTAD, about $80 \%$ of the volume of international trade in commodities is transported by ships through seas. Moreover, the percentage is even higher for most developing countries [2]. In 2021, the world fleet deadweight tonnage (merchant ships of 100 tons and above) increased by $3.04 \%$ compared to 2020 [2]. Furthermore, the demand for containers is constantly increasing, making shipping companies adapt to the current situation. Deployment of mega container ships is one of the solutions addressing the problem [3,4]. At the beginning of the 21st century, more and more of the world's cargo was transported in mega container ships (cargo capacity greater than 10,000 20 foot-equivalent units-TEU). Between 2011 and 2021, their proportion of carrying capacity increased from $6 \%$ to almost $40 \%$. However, due to the COVID-19 pandemic, newbuilding orders declined by 16\% during 2020.

Nevertheless, despite the ongoing pandemic, at the beginning of 2021, shipping companies reacted to the capacity constraints with a surge of new orders, especially for container ships and LNG carriers [2]. Transporting containers in megaships is more profitable for routes with higher freight rates, but accidents involving these ships might be catastrophic. The disruption of maritime traffic, especially in sensitive areas, seriously affects the global 
economy [5]. For example, the recent Ever Given mega container ship incident while transiting the Suez Canal caused supply chain disruption and tremendous economic losses. The Ever Given, grounded at the southern end of the Suez Canal due to its diagonal position, caused a blockage of the Suez Canal for six days and had a negative impact on trade between Europe and Asia [6]. It was estimated that USD 9.6 billion worth of trade was held up each day due to the blockage [7]. However, not only mega container ship accidents can produce a significant economic loss. Accidents involving large tanker ships can have catastrophic consequences for the environment (oil pollution) and consequently negatively affect marine industries. Therefore, all shipping stakeholders are making immense efforts to mitigate the hazards and reduce the number of marine accidents due to their adverse effects on the maritime industry.

Marine accidents are unwanted harmful events, often with catastrophic consequences, including fatalities, injuries, cargo loss, equipment damage, and environmental pollution [8]. There are two approaches to avoiding accidents at sea: corrective and proactive [9]. The corrective approach includes accident investigation and analysis to reveal immediate and root causes. Based on investigation findings and analysis, corrective actions and conclusions are proposed that might positively affect maritime safety and reduce the number of accidents. It is called the corrective approach because an accident already occurred, and harm was done (a usually expensive way to improve safety). The second approach can be considered proactive because it includes investigating and analysing near-miss (or close-call, near-hit) events. A near miss can be defined as [10-13] "a sequence of events and/or conditions that could have resulted in a loss. This loss was prevented only by a fortuitous break in the chain of events and/or conditions. The potential loss could be a human injury, environmental damage, or negative business impact (e.g., repair or replacement costs, scheduling delays, contract violations, loss of reputation)".

Since near misses share immediate and root causes with accidents, near-miss investigation and analysis might prevent similar events in the future. Therefore, it could be considered "the less expensive" way to reduce marine accidents and improve safety at sea. Thus, all high-risk industries, including maritime, need to avoid accidents and increase safety.

The International Maritime Organization (IMO) introduced the International Safety Management (ISM) Code, aiming to improve safety at sea. The ISM Code requires that companies establish a safety management system (SMS) to ensure the safety of the ship and marine environment. According to the ISM Code (Section 9.1) [14], "the SMS should include procedures ensuring that non-conformities, accidents and hazardous situations are reported to the Company, investigated and analysed with the objective of improving safety and pollution prevention". The IMO [10] stated that "companies should investigate near-misses as a regulatory requirement under the 'Hazardous Occurrences' part of the ISM Code". Consequently, near-miss reporting and analysing are compulsory in the maritime industry. Investigating near misses is considered an integral component of continuous improvement in marine safety management systems. However, despite the reporting requirement, near misses in the maritime industry seem to be underreported $[9,13,15-17]$.

Investigating and analysing near-miss events could facilitate with estimating the risk level of a specific ship and steer the researchers towards the most significant problems in the safety management system implemented onboard. This paper aims to identify safety areas needing improvement by analysing reported near-miss events. Based on the data obtained, suggestions for safety improvements in shipping are proposed. The paper is organised as follows: A literature overview is given in Section 2, methodology is presented in Section 3, Section 4 encompasses the research results, the discussion is given in Section 5, and concluding thoughts together with suggestions for improvements, research limitations, and future research directions are given in Section 6.

\section{Literature Review}

Near-miss systems in shipping have been the topic of several studies. An overview of near-miss management systems (NMMSs) in shipping was given in [9]. A NMMS is a 
system for dealing with near misses, and it is used as a tool for accident prevention and safety improvements. It usually consists of six to eight phases, and the authors presented the phases as identification, reporting, prioritisation, distribution, cause analysis, solution identification, dissemination, and resolution.

In [18], Erdogan tried to find the best practices for near-miss reporting in the maritime industry and the role of near-miss reporting in creating and enhancing safety culture from the seafarers' point of view. Four shipping companies that achieved a high level of safety culture and could be considered representatives of safety culture and best practices were surveyed. He concluded that not all observed near misses are reported, even in these companies, due to reporting barriers. However, a "no blame" culture was reported as being achieved, which was a considerable step towards excellence. Furthermore, companies invest in the training of seafarers and encourage open communication and a trusting atmosphere between personnel. Another important gain to implementing reporting best practice was teamwork, which was apparently achieved in all surveyed companies. The main identified reporting barriers are as follows: It is not clearly defined what to report (definition of a near miss), some seafarers do not report because they believe that others will think that they are incompetent at the job, some crewmembers think that there is no time to write down the reports, some seafarers take actions to prevent near misses from recurring but do not make an official report, and lack of shipboard leadership commitment.

Oltedal and McArthur, in [19], studied the factors influencing reporting practices and their frequency in the maritime industry. They pointed out that underreporting in shipping is a significant problem that needs to be dealt with. Their study confirmed that reporting frequency might be increased if crewmembers are highly competent, interpersonal relationships between crewmembers are good and open, company management is safety oriented, and feedback is given on each reported event. However, it was pointed out that the identified factors should not be addressed separately since they are all mutually dependant. Another important finding was that crewmembers who have worked with their superior officer for more than one year tend to report more frequently.

Lappalainen et al. [20] studied poor incident reporting and its reasons in the Finnish shipping industry. The authors found that seafarers feel ashamed to report an incident that was caused by their behaviour. The interviewed seafarers considered reporting to be complicated and believed there is insufficient time or resources to make all necessary incident reports. Furthermore, not receiving adequate feedback from reported events, unclear responsibility for making reports, and a clear definition of what is to be reported negatively affected reporting frequency. The existence of blame culture also made seafarers reluctant to report adverse events, although the authors found that safety culture in the surveyed companies improved.

Storgård et al. [21] studied internal and national reporting systems in Sweden and Finland to find best practices and facilitate reporting in shipping. They found that anonymity of reports improves reporting and helps to create a no-blame culture. One of the conclusions was that the aim of reporting system should not be the number of reports, but their quality. As in other studies, they also found that not all observed incidents and near misses are reported. Recommendations for improvement of reporting included a proposal to actively involve reporters in the reporting system and ask them to recommend corrective actions that might help prevent the same events in the future. In addition, during shipboard meetings, feedback on reported events should be given and experiences shared; that way, reporters would feel that reporting near misses makes sense and improvements are being made. Finally, the authors concluded that reporting must be as simple as possible, and dissemination of the lessons learnt from incidents and near misses must be enabled with a broader audience.

Seafarers' perception of near-miss reporting was presented in [22,23]. In [22], it was found that seafarers believe that reporting is an obligation rather than a necessity to improve safety, whereas companies' representatives consider it a safety indicator. Both shipboard and shoreside personnel agreed that an increased number of reports does not necessarily 
mean increased shipboard safety; however, reporting significant and rare events might be a step forward. Analysis of such events might produce valuable safety data that could help improve safety at sea [22].

That increased reporting does not necessarily imply a decrease in the number of incidents was argued in $[13,24]$. The author analysed reported hazards, near misses, and incidents and found no relation between them. Reporting quotas and incentives offered for near-miss reporting might be seen as an obstacle to safety improvements since some seafarers reported that in the absence of actual near-miss events, seafarers report "imaginary" events [23]. That could threaten safety improvements, since the conclusions made are not based on actual hazardous events.

Zhou et al. [12] developed a model to predict the risk level of near-miss events during a tanker ship voyage. Their study applied an adaptive neuro-fuzzy inference system (ANFIS) that included four variables contained in the near-miss report (type of operation, ship's position, onboard location, and harm potential). Furthermore, they analysed direct, indirect, and root contributory factors. The results revealed that poor housekeeping was the most represented direct contributory factor, whereas the human factor was the most represented indirect contributory factor. Furthermore, training and procedure were recognised as measures that could minimise near-miss incidents. In addition, they found that only $4 \%$ of the reported near-miss events fell into the high-risk-level category.

Besides the shipping industry, near-miss reporting and learning from incidents was also studied in other high-risk industries [25], for example, steel [26], construction [11,27,28], chemical [29], mining [30,31], and nuclear [32]. Jones et al. [33] stated that a near miss should be considered an early warning signal that an accident might occur, that reporting and investigation must aim to prevent similar events and accidents in the future, and that it should be included in safety management systems in industrial facilities. Vastveit et al. [29] stated that organisations working "with complex and high-risk technologies in volatile environments" must proactively prevent possible accidents; they cannot afford accidents to happen since the consequences might be disastrous. Those organisations must utilise all opportunities to learn and improve safety. Zhou et al. [11] presented eight phases of the near-miss management process in construction management projects. The authors performed a case study and presented the utilisation of NMMS to assist in construction safety management. Haas et al. [31] studied near-miss reports in the mining industry to improve organisational management. The researchers visited three mine locations and gathered near-miss reports. The collected near-miss reports were rated using a risk assessment matrix. Then authors checked whether there was a relationship between risk rank and corrective action. The test results were significant, and corrective actions of implementing safe working procedures were associated with higher-risk-level events, whereas elimination and engineering were associated with lower-risk-level events.

According to the available existing literature, some of the reasons for not reporting all observed near misses might be $[9,18-21,34-41]$ the existence of blame culture, identifying the near-miss event, the complexity of reporting forms, leadership style onboard the ship, and lack of shore management commitment. All these barriers need to be overcome for a seafarer to report a near miss. However, once identified and reported (first two phases of NMMS), there is a need to prioritise near-miss events (rating by utilising a risk assessment matrix, for example) since it is practically impossible to rate all reported near misses in large companies [26]. Gnoni and Saleh [42] compared the prioritising phase with medical triage, insinuating that high-risk near-miss events should be prioritised over low-risk ones. Following prioritisation, reported near-miss events would either be analysed or not (highrisk events must be analysed). Finally, corrective actions and identification of solutions would lead to dissemination and resolution (verifying that the solutions are applicable on a specific ship and adequately implemented). The dissemination of near-miss report analysis and corrective actions, together with the resolution, is crucial for learning from incidents (LFI) $[29,43]$, and the maritime industry benefits from it. As a result, safety might be improved and accidents with similar causes prevented. 
Previous studies on maritime near-misses generally dealt with reporting and learning from analysed near-miss reports, but studies dealing with improving safety management by analysing near-miss reports are lacking. Nevertheless, analysis of near-miss events might provide information about weak points in the safety management system and facilitate safety improvements. Furthermore, analysis of reported events can contribute to safety efforts in shipping and highlight the areas that need special attention and improvement. Therefore, this paper aims to recognise safety areas that could be improved by analysing reported near misses. In addition, report analysis could provide a better insight into the near-miss system and identify possible shortcomings. Finally, the findings could serve as a topics of toolbox meetings and assist in the creation of improved hazard analysis and safety measures used to avoid future near-miss events that could exacerbate to become accidents.

\section{Methodology}

The research flowchart diagram is presented in Figure 1.

\begin{tabular}{|c|c|}
\hline \multicolumn{4}{|c|}{ Step 1. Data collection } \\
Company safety and near-miss policy \\
collected
\end{tabular}

Figure 1. Research flowchart diagram.

In step one, the authors collected near-miss reports from one tanker ship. Besides nearmiss reports, researchers were also given the company's near-miss management system policy. Due to the hazardous cargo they transport, it is believed that tankers, in general, are dangerous types of ships; therefore, more stringent safety regulations apply to them. Therefore, one company handling these types of ships was selected for the study. The researchers asked the company for completed near-miss reports, and in return, reports from one tanker ship were received. The ship was an Aframax oil tanker (delivered in 2006, overall length $253 \mathrm{~m}$, breadth $44 \mathrm{~m}$, deadweight capacity 115,090 tons) that complemented 21 crewmembers. The crewmembers' nationalities were mixed: The officers were Croatian primarily, followed by Finnish, Russian, and Indian, and the ratings were Indonesian. The tanker was mainly trading in Europe and North Africa.

Although the shipping company and tanker name are not revealed in the paper due to confidentiality, they are referred to as Company and Tanker. Since the authors served as maritime professionals on several ship types during their sea time, there was no need to visit the vessel personally. Therefore, insight into near-miss reports and company safety and near-miss policies was sufficient for adequate analysis.

It must be noted that the results of a case study should be observed with caution since they cannot be generalised. However, the results obtained are valid for the tanker industry 
as per the authors' expert opinions and could provide valuable insights for further studies for other ship types and serve as a topic for safety meetings.

\subsection{Near-Miss Management System on Board}

Step two included analysis of the near-miss management system implemented onboard. The near-miss management system policy was included in the ship's safety management system. It was stated, "All incidents, accidents and high-profile near misses shall be thoroughly reported, investigated, and evaluated by senior management in order to:

- $\quad$ Learn from the experience;

- Implement preventive measures;

- Fulfil any legal and/or regulatory requirements; and

- Identify the root cause(s) in order to determine short term and long term corrective actions as part of the continuous improvement process".

The company's SMS stipulated that written reports should be forwarded to a designated person ashore (DPA) using the Near-Miss Report Form. The captain of the ship and DPA are responsible for initiating the investigation and, when appropriate, ensuring that immediate corrective actions were initiated. It is required to carry out a full investigation following the recommendation of the IMO Code of the International Standards and Recommended Practices for a Safety Investigation into a Marine Casualty or Marine Incident. The investigators are supposed to make suggestions for improvement and include them in their reports. The shore-based management team should discuss and evaluate the required corrective action(s), implementation plans, and responsibility for follow-up until the effectiveness of the corrective actions is determined. The best practices used might have to be reconsidered, and corrective actions to one or more of the following may result in:

- Procedures and checklists;

- Equipment, system, and materials used;

- Safety equipment to be used; and

- Training of individuals or groups of personnel.

The results of the incident or high-profile near-miss investigation and the recommended corrective actions are supposed to be disseminated to all personnel in the organisation via the Fleet Letter system.

Each crewmember can report a near-miss, and reporting forms are available in a special box in an alleyway onboard the ship. Besides filling in the form from the box, each crewmember can report a near-miss to the chief officer verbally, and he would submit it in writing. Thus, near misses are reported on paper and then scanned and sent to the company via e-mail. The near-miss report forms contained the following information:

- Ship name;

- Date;

- Report number;

- Geographical position or name of the port where the near miss occurred;

- Onboard location of the near-miss;

- Ship's position at the time of the near miss (at sea, pilotage, moored, anchored, dry dock);

- Risk;

- Brief description of the near miss;

- Corrective action taken;

- Additional corrective action if deemed required; and

- Name and the rank of the reporter.

There was also a part to be completed by the office, and it contained the following information:

- Date when received at the office;

- Whether additional corrective action was required;

- Whether investigation was required;

- Suggestions for improvements to avoid recurrence and closure date;

- Company manuals affected; 
- Date of completion of corrective action; and

- $\quad$ Signature of the DPA or deputy.

It should be noted that the company expected that each ship report at least one near miss per week, making a total of 52 reports per year.

\subsection{Data Classification, Coding and Analysis}

In total, there were 309 processed near-miss reports from the period 2009-2017. The authors paid particular attention to the following variables: the onboard location where the near miss occurred, the ship's position at the time of the near-miss event, risk, description of the near miss, corrective action, whether additional corrective action was deemed necessary, and whether the part to be completed by the office was completed.

\subsubsection{Near-Miss Classification}

Each near-miss report was classified according to type in order to facilitate handling and sorting. Since the description of the near miss could contain several sentences, and there were different wordings used in the reports, the authors decided to classify each report according to inadequate action that could lead to an incident. Based on the near-miss descriptions in reporting forms, the researchers assigned the following types to the reports: asphyxiation hazard, electrical hazard, equipment failure, fall from height, hit by/struck by, housekeeping, lock out/tag out, process/procedure related, slip/trip hazard, third-party violation, and use of personal protective equipment (PPE). For example, one near-miss description was, "few oily gloves found in the midship store without attention". The nearmiss was risk of fire, as marked in section "near-miss with risk for". The authors classified it as "housekeeping" because inadequate disposal of oily gloves might produce accidental fire or self-combustion of some materials that could be found in the ship's midship store.

\subsubsection{Estimating Near-Miss Risk Levels}

Furthermore, a qualitative risk assessment of collected near-miss reports was performed to estimate their possible negative impact. The reported near-misses were classified according to risk level. The authors used a $5 \times 5$ risk assessment matrix to estimate the risk level of reported near-miss events. Although a $4 \times 4$ risk assessment matrix is recommended in [44], it was decided to use a $5 \times 5$ matrix, as it is widely used in various industries [45]. Estimating risk level was performed by multiplying the probability of an adverse event and the severity of the consequence that the near-miss event could have caused. The probabilities assigned in the matrix were rare (1), unlikely (2), moderate (3), likely (4), and almost certain (5) [45]. Possible consequences were negligible (1), minor (2), moderate (3), major (4), and catastrophic (5) [45]. The possible near-miss risk levels used in this paper are low risk (score 1-4), moderate risk (score 5-8), high risk (score 9-12), and critical risk (score 15-25).

Three authors were assigned to estimate risk levels based on collected reports, emphasising sections dealing with near-miss descriptions and type of risk. The authors who could be considered experts in the field performed a qualitative risk assessment of each reported near miss. Two authors had sailed on tankers as safety officers and captains, and the third author had sailed on other ship types as a safety officer. The authors met on several occasions and performed near-miss risk assessments during meetings and discussions. Final risk scoring for each near miss was obtained based on the authors' consensus.

Furthermore, estimating near-miss risk level is a comprehensive and challenging task, and the authors had to move beyond what actually occurred and look for all possible outcomes to score a near-miss risk; thus, it was decided that the external expert would evaluate and validate the scoring. Therefore, 30 reports were sent to an external expert (captain on tanker ships) for risk assessment. The received scoring was in line with the authors' assessment. Only two reports were scored slightly differently, namely, one report description was, "Spare valve in deck store aft found not properly lashed", and the authors assigned it to the low-risk category (scored as 4). The external expert also assigned a near 
miss to the low-risk category but gave it a score of 2. The expert's opinion was that an unlashed valve is unlikely to move, and if moving, it could cause negligible consequences. The second near-miss report description was, "It has been noticed that one crewmember was chipping on deck without any eye protection". The authors assigned it to the moderaterisk category and gave it a score of 8 . The external expert gave it a score of 6 , placing it in the moderate-risk category. Thus, differences were minor, and near-miss risk levels remained unchanged after the assessment of the external expert.

\subsubsection{Coding Corrective Actions}

Following estimation of the near-miss risk level, the corrective actions were analysed, and each was assigned one code. The researchers were guided by a hierarchy of controls $[31,46,47]$ (Figure 2) for coding corrective actions, with two differences. "Administrative controls" were coded as "implement safe working practices", because while examining reported corrective actions, it was found that all corrective actions taken within "administrative control" could be classified under the implementation of safe working practices (additional training was not given, and policies and procedures were not improved or altered). Furthermore, the "not fixed" code was used in this study for all near-miss reports for which corrective action could be considered not completed, in process, or simply inadequate. Therefore, the corrective actions used in this paper are elimination, substitution, engineering controls, implementing safe working practices, PPE and not fixed. The most effective measure in the hierarchy of the control system is elimination, where the hazard is physically removed, whereas the least effective is PPE, where persons involved in work execution are required to use adequate protective equipment throughout the work. For example, one near-miss description was, "During anchoring, winch operate crewmember did not wear safety protective googles". Therefore, the near-miss report type was classified as "Use of PPE". The corrective action written in the report was, "Officer in charge sent him to bring googles. PPE must be used at all times". An additional corrective action stated was, "To be discussed on safety meeting". Therefore, the corrective action was coded as "PPE".

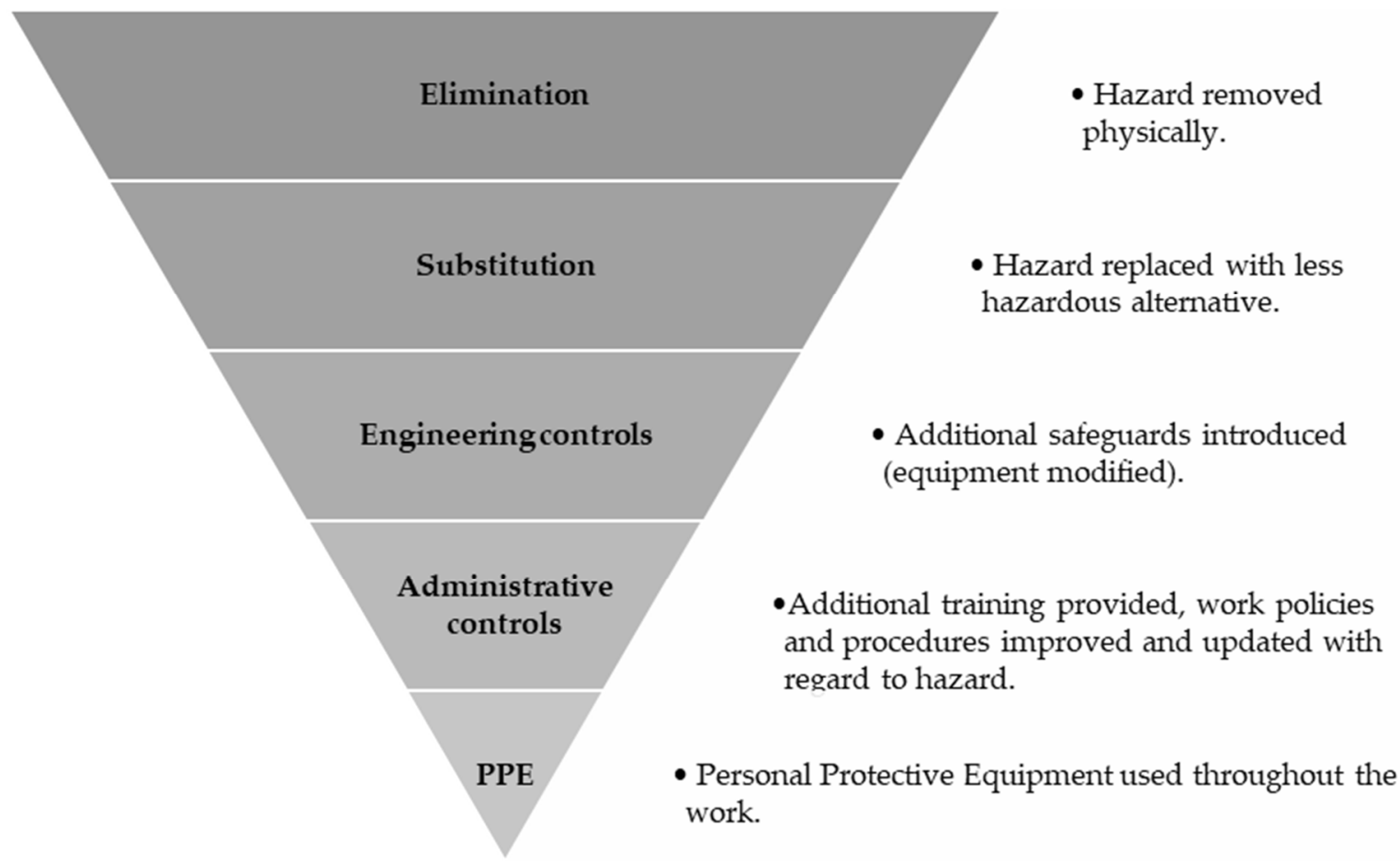

Figure 2. Hierarchy of controls (elimination is the most effective, and PPE is the least effective) [31,46,47]. 


\subsubsection{Coding Ship's Positions and Onboard Locations}

The ship's positions were coded according to the near-miss report form: at sea, anchored, moored, pilotage, and dry dock. Onboard locations were divided into deck area, engine room area, navigating bridge, accommodation, and ballast tank. The deck area included forward mooring area, poop deck, pumproom, midship stores, cranes, lifeboats, gangways, and deck stores. Accommodation included all areas within the accommodation such as the galley, pantries, storerooms, recreation rooms, gymnasium, alleyways, stairways, and cabins.

\subsubsection{Near-Miss Report Analysis}

Based on the methodology used, the near-miss reports were classified and coded, followed by statistical analysis. The Chi-square test of independence of variables [48] (statistical software R) was used to determine whether there was a relationship between (a) near-miss risk levels and near-miss corrective actions, (b) near-miss types and near-miss corrective actions, (c) ship's positions at time of near miss and near-miss risk levels, and (d) onboard location where near misses occurred and near-miss risk levels.

\section{Results}

When analysed according to the onboard location where the near miss took place, the most reported near misses (198 reports) were connected to the deck area, whereas the accommodation was connected to 52 reports. Furthermore, there were 43 reports regarding events in engine room areas, 10 reports connected with the navigating bridge, and six reports on the ballast tanks. Next, it was necessary to analyse the near-miss reports according to the ship's position at the time of the event. More than $80 \%$ of the near misses occurred while the ship was proceeding at sea (131 reports) and anchored (128 reports). The remaining near misses occurred while moored (36 reports) and during pilotage (14 reports). There were no reported near-miss events during dry dock. Further analysis of the near-miss reports showed that the most significant number of near misses was related to housekeeping (22.3\%), equipment failure (16.8\%), use of PPE $(15.9 \%)$, and processes/procedures $(15.9 \%)$, as presented in Figure 3.

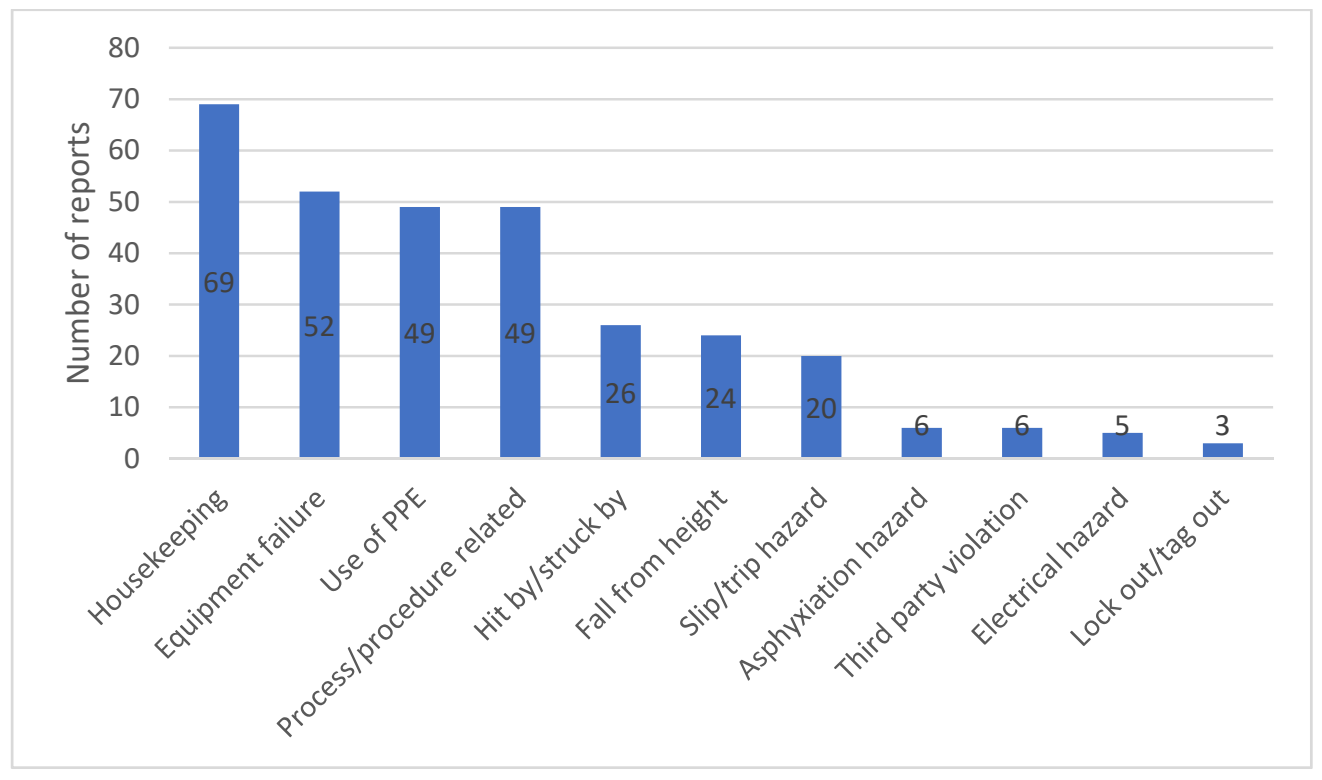

Figure 3. Frequency of near-miss types.

Therefore, it might be prudent to pay special attention to these near-miss types since they represent $71 \%$ of the total number of reported near misses. 
When analysed according to risk level, 35.9\% of the near misses were low risk level (Figure 4). Moderate-risk-level near-misses represented 35.6\% of the total reported near misses, whereas $25.9 \%$ were high-risk-level near misses and $2.6 \%$ were critical-risk-level near misses. Therefore, it would be prudent to investigate and analyse at least all highand critical-risk-level events. However, a review of safety records from the case-study ship revealed that investigations and analyses were not performed; only immediate corrective actions were recorded and implemented.

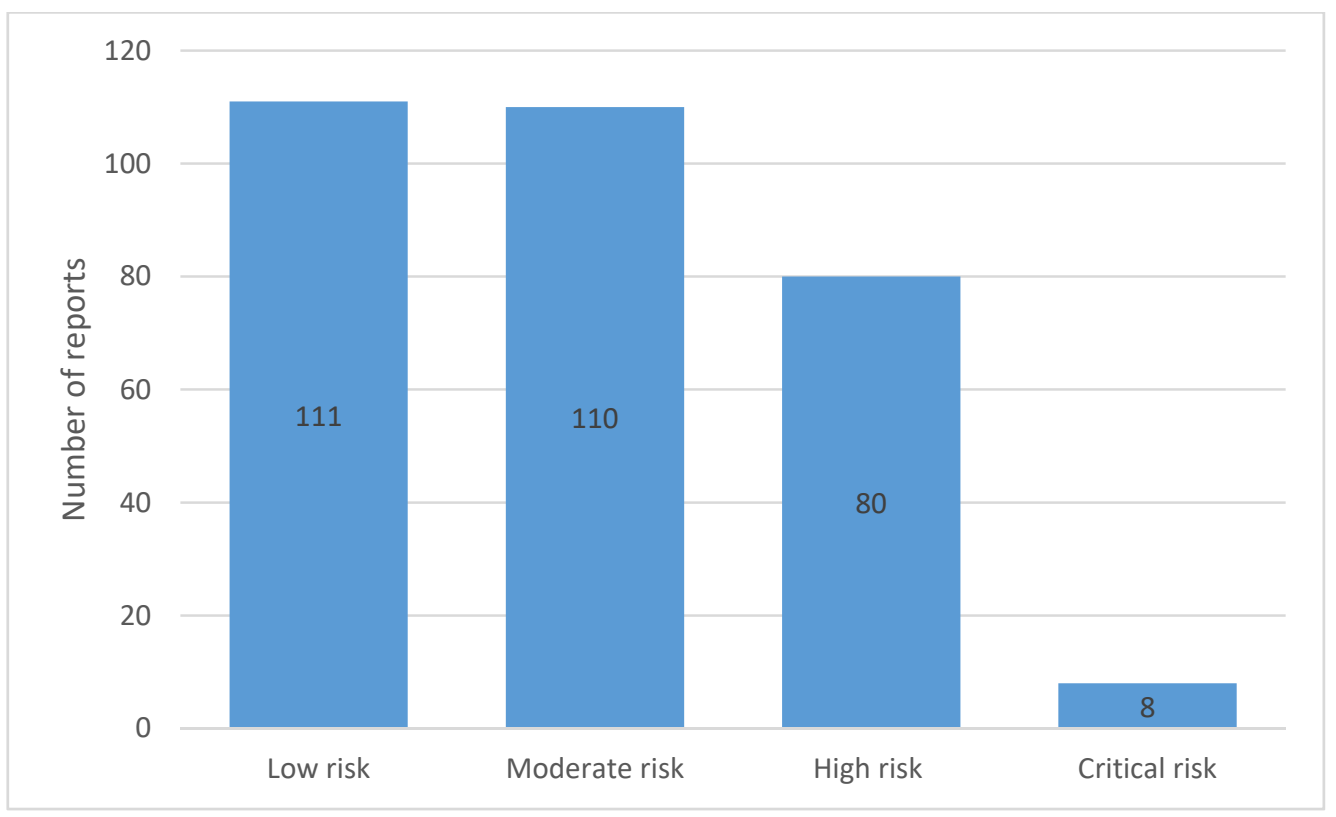

Figure 4. Risk levels of analysed near-miss reports.

As presented in Figure 4, 2.6\% of reports were near misses with critical risk levels, and they included housekeeping, use of PPE, asphyxiation (two reports each), equipment failure, and third-party violation (one report each). Most of the high-risk-level reports included fall from height, process/procedure related, equipment failure, and use of PPE (Figure 5). As presented in Figure 5, housekeeping, hit by/struck by, and slip/trip hazards are generally lower-risk-level events, whereas lock out/tag out is a high-risk-level event that requires careful planning and safety consideration.

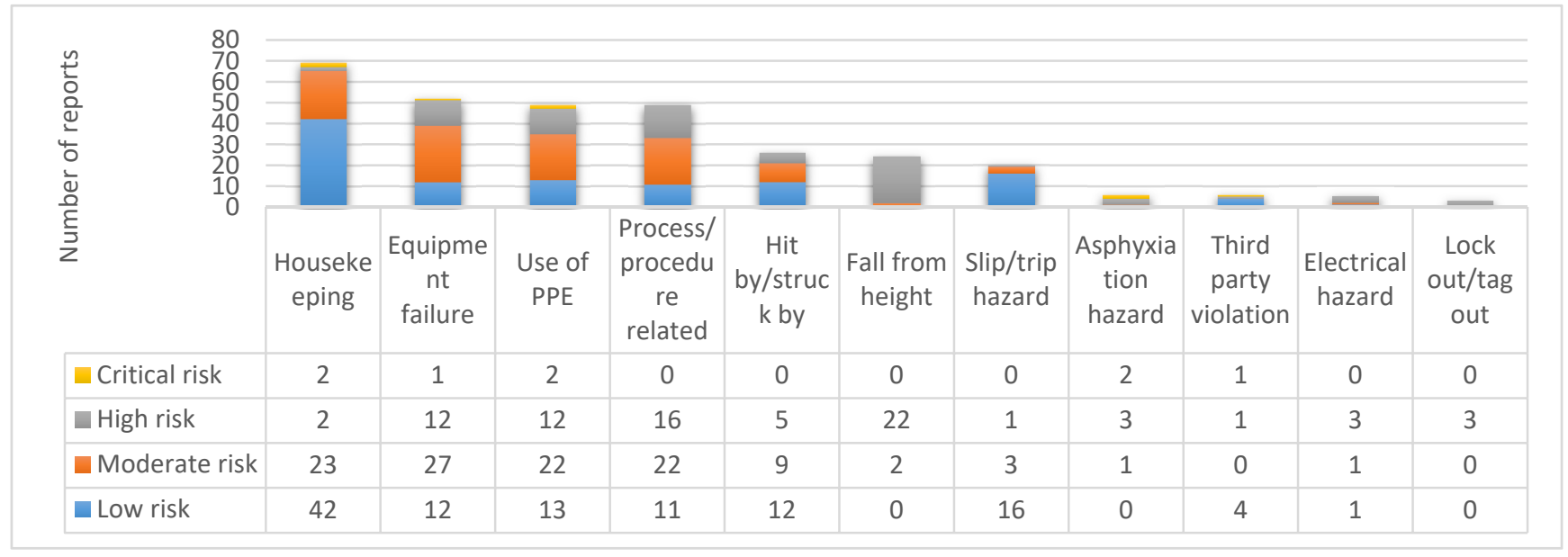

Figure 5. Near-miss risk levels by near-miss type.

Near-miss reports on falling from height include only moderate and high risk levels and thus can be regarded as a highly hazardous near-miss type. Working at height is 
hazardous work, and it requires a formal risk assessment to be performed and issuance of a working permit before work starts. Although, unquestionably, all potential risks and mitigating actions were included in the risk assessment form, and again in the work permit, somehow there were always near misses where it was stated that procedure was not followed. For instance, one reported near miss stated, "one crewmember was noticed working on the outer side of lifeboat without wearing a safety harness". As wearing a safety harness is included in PPE that must be adequately used while working at height, it might be incomprehensible to conclude how this near miss occurred. However, the corrective action was coded as "PPE", meaning that work was immediately stopped and the crewmember was instructed to use a safety harness adequately. However, according to the hierarchy of controls, PPE is the least effective measure that could be used. Therefore, there is a need for additional safety training emphasising adequate PPE usage and following company procedures. In addition, as mentioned in some reports, PPE usage is a subject that needs to be pointed out during monthly safety meetings. Additional training and frequent discussions, followed by extensive preparations before work execution, might lead to increased safety awareness and a decrease in near-miss events.

When corrective actions were analysed according to risk level, it was found that most of the corrective actions were about implementing safe working practices, followed by adequate usage of PPE (Figure 6). Corrective actions that include elimination were performed in only 35 reports, and 34 were categorised as low and moderate risk levels. There were five high-risk-level reports and one critical one under the corrective action "not fixed", meaning that such hazardous events were not resolved and actions were not taken to prevent a recurrence. Therefore, it is of the utmost importance to investigate critical-risk-level near-miss reports as soon as possible to find the root causes and establish safeguards. In addition, as presented in Figure 6, corrective actions including PPE were mostly represented in high- and critical-risk-level near misses.

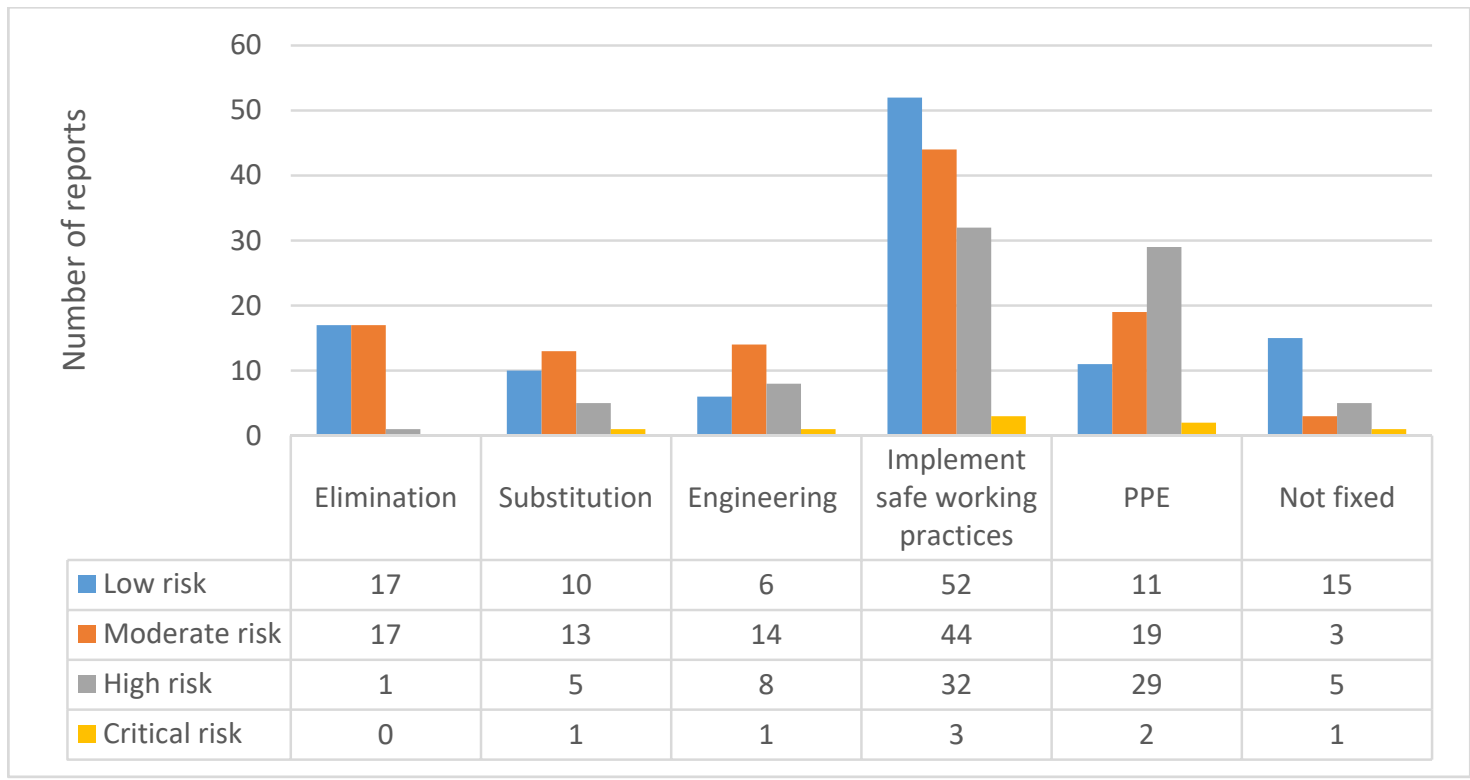

Figure 6. Corrective actions by near-miss risk level.

Figure 7 presents near-miss types by corrective action taken. Housekeeping was mainly associated with elimination and implementing safe working practices, whereas equipment failure mainly involved substitution and engineering. PPE was the most common corrective action for the use of PPE and fall from height near-miss types. Process/procedure related, hit by/struck by, slip/trip hazard, asphyxiation hazard, and lock out/tag out near misses were corrected mainly by implementing safe working practices. Third-party violations 
were mainly reported as not fixed, whereas corrective measures were equally represented for electrical hazard near-miss types.

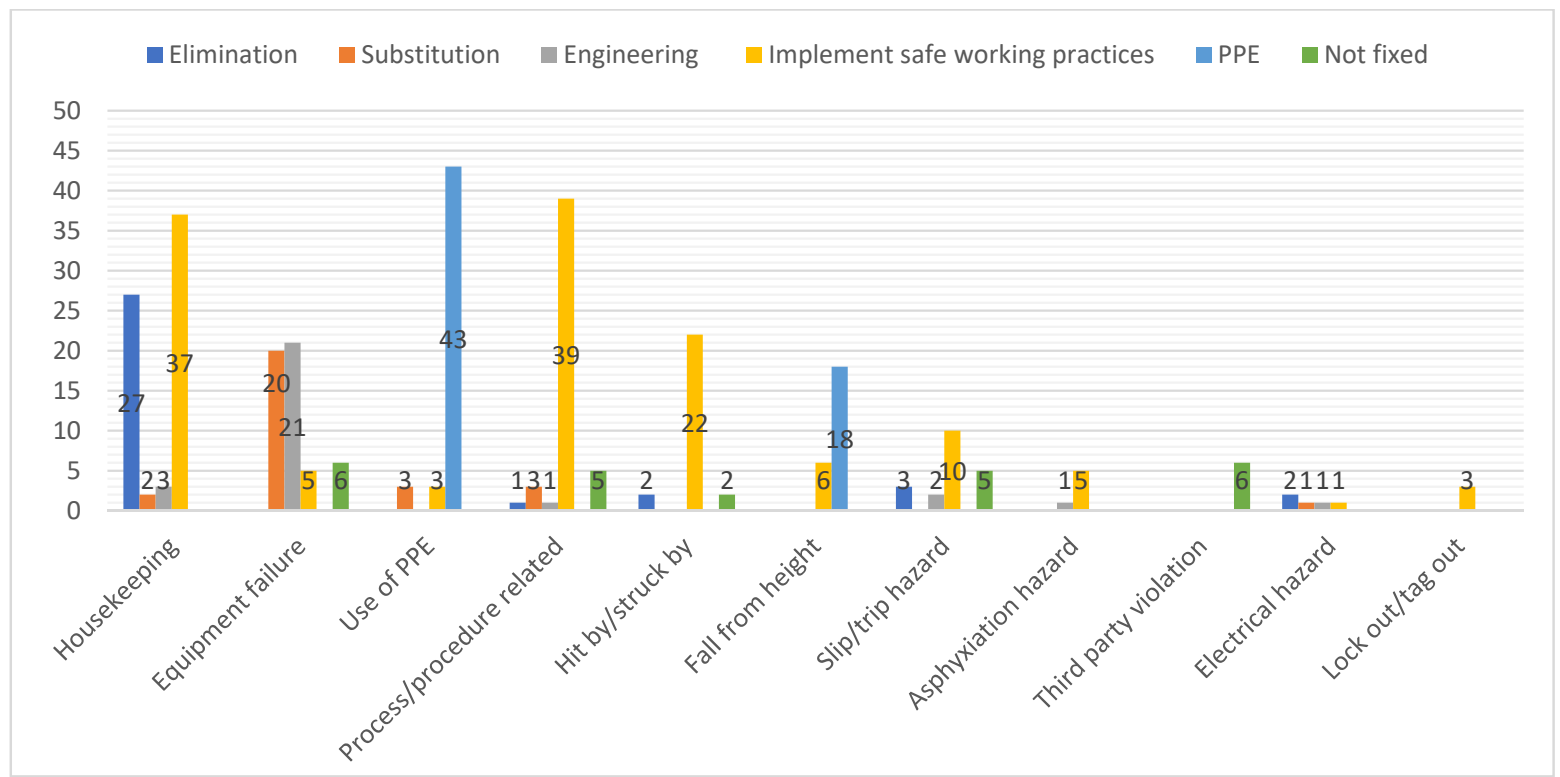

Figure 7. Near-miss types by corrective action.

Most of the reported near misses occurred in the tanker's deck area. When analysed according to risk level, it was found that most represented risk categories were low and moderate risk, followed by high risk (Figure 8). The accommodation and ballast tank areas included less hazardous near misses (primarily low and moderate risk levels), whereas the engine room included mainly moderate and high risk levels. The navigating bridge also presents a hazardous area, as it is where the ship is steered, and near-miss reports included third-party violations (for example, ships contravening collision avoidance regulations). Due to the relatively large number of higher-risk-level reports for the engine room and navigating bridge, it can be concluded that these onboard locations are more hazardous, and there is a need to pay more attention during work performance.

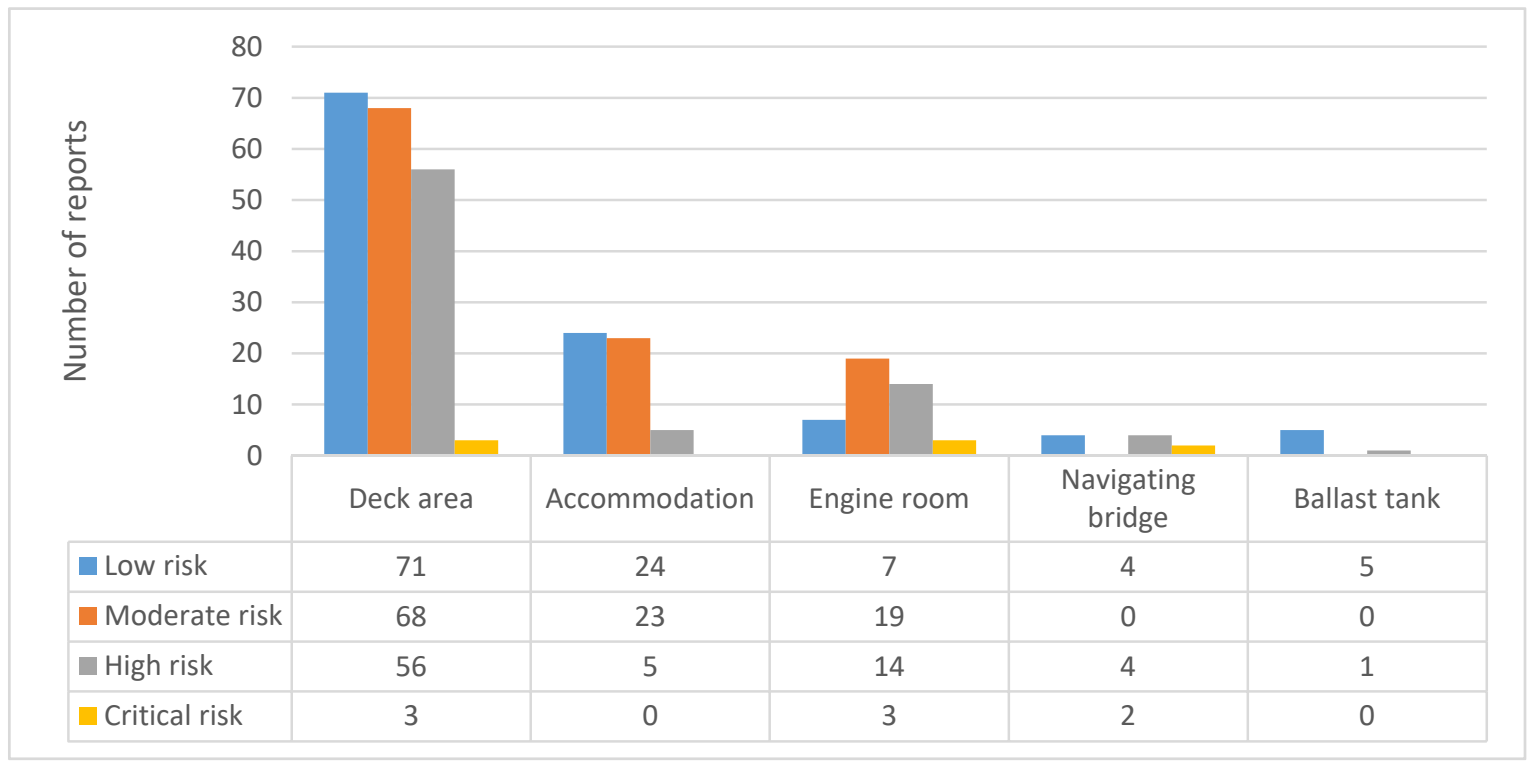

Figure 8. Onboard locations by near-miss risk level. 
Figure 9 presents ship positions by recorded near-miss risk levels. Most of the events occurred while the ship was at sea and lying at anchor (83.8\% of recorded near miss). A significantly smaller number of events $(16.2 \%)$ was recorded during the pilotage and while moored at berth. However, most of the work onboard a ship is performed during the voyage at open sea and while anchored, and it might be expected that more adverse events would happen during these times. From Figure 9, it can be concluded that near-miss risk levels are not related to the ship's position at the time of the occurrence because there were no significant differences between groups.

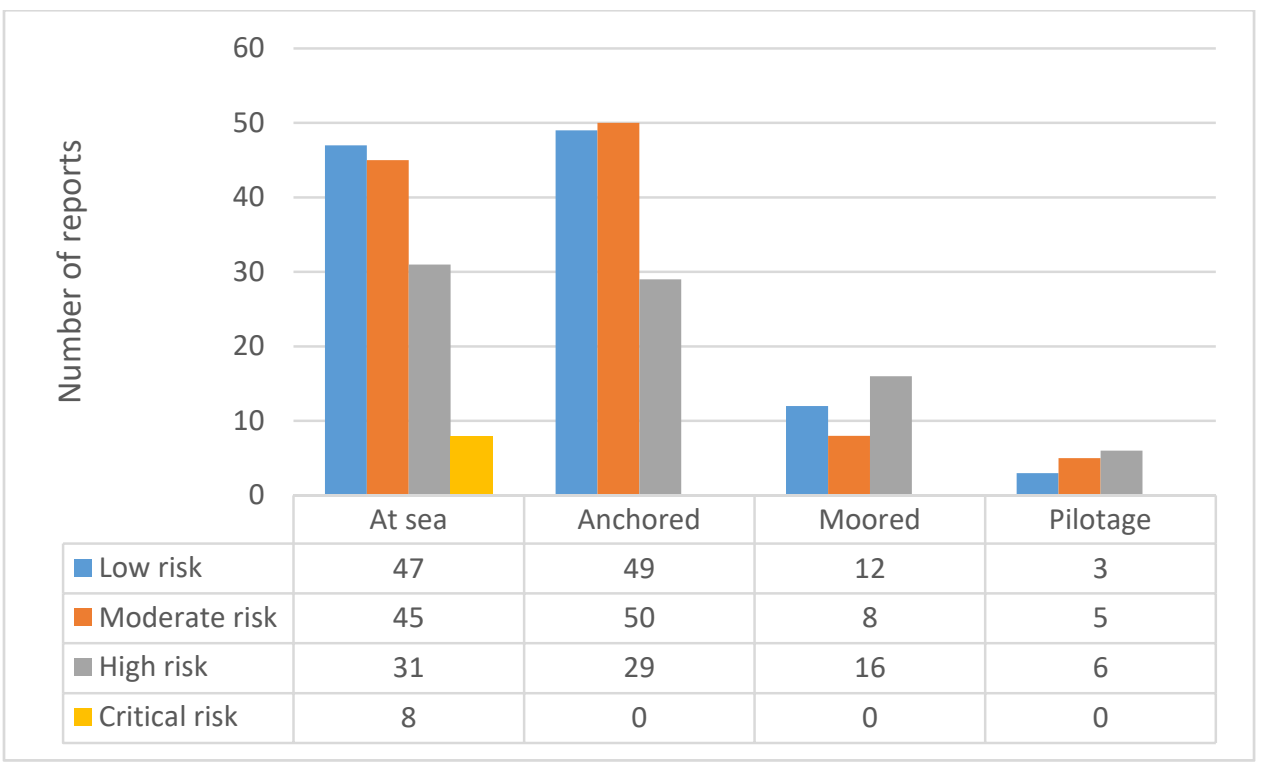

Figure 9. Ship position by near-miss risk level.

Finally, the results of the Chi-square test of independence of variables were significant for the relationship between near-miss risk levels and near-miss corrective actions $\left(\chi^{2}=44.271, \mathrm{df}=15, p\right.$ value $\left.=0.000\right)$, near-miss types and near-miss corrective actions $\left(\chi^{2}=552.028, \mathrm{df}=50, p\right.$ value $\left.=0.000\right)$, and onboard locations where near misses occurred and near-miss risk levels $\left(\chi^{2}=51.711, \mathrm{df}=15, p\right.$ value $\left.=0.000\right)$. The results were insignificant for the relationship between ship position at the time of the near miss and near-miss risk level $\left(\chi^{2}=23.479, \mathrm{df}=15, p\right.$ value $\left.=0.074\right)$.

\section{Discussion}

During a review of reported near misses and near-miss policy (including parts of safety management) in our case study, it was found that there was no procedure established for estimating near-miss risk level (scoring) and giving priorities. Prioritisation is a crucial NMMS phase since "serious" near misses that require investigation are revealed and further processed. The procedure is as follows: The ship prepares a near-miss report and sends it to the office, where the DPA or deputy reviews it. Nevertheless, there is no procedure for rating near-miss risk severity for the office as well.

Therefore, the development of a step-by-step near-miss prioritising phase is recommended. Furthermore, as estimating near-miss risk level is a prerequisite for near-miss investigation, it is of immense importance for a successful near-miss management system. Consequently, it is suggested that shipping companies develop near-miss risk-scoring procedures using a simple risk assessment matrix. In that way, higher-risk-level near misses would be immediately recognised onboard a ship, and investigations could be immediately launched, aiming to identify immediate and root causes and to propose corrective actions. However, proposed corrective actions that might include revisions of policies and procedures should be discussed with shipboard personnel before implementing to address all possible shortcomings and verify their applicability in practice. 
Higher-risk-level near-miss reports should generate safety management revisions and modifications of processes and procedures onboard ships. Corrective actions should be immediate, and a holistic approach is required. Although some near-miss events are recurring and might even transmute in more severe incidents, corrective actions only deal with symptoms.

Another issue recognised during analysis was the section of the near-miss report form that was assigned to be filled by the office. When near-miss reports filed on the tanker were reviewed, it was found that this section was left blank in all reports, meaning that there was no direct feedback as there should have been (directly on the form). The company was disseminating "near-miss information" to the whole fleet twice a year, where near-miss statistics for the company were given, or near-miss reports that were considered critical or high risk were presented together with corrective actions taken by the office and recommendations for the fleet. Nevertheless, as already stated, the corrective action taken by the office and suggestions for improvements were not recorded on the report forms as they were supposed to be, which might have helped build a reporting barrier to crewmembers, as they felt that reports distributed to the company were not directly acted upon. Including additional corrective actions and recommendations from the office on near-miss report forms would facilitate follow-up actions and improve the company safety management system, and would surely be seen as a significant step towards the onboard safety improvement during safety management inspections and reviews. Therefore, the inclusion of corrective actions and safety improvement suggestions from the office on the near-miss report is recommended.

Corrective actions could be classified as immediate and follow-up actions. The analysis of the reports showed that all the corrective actions were immediate-they were directed towards the immediate cause of the near miss, not the root cause. Although there was a section intended for such corrective actions (additional), it was used to add corrective actions to mitigate or remove the direct cause of the near miss, while the latent one was still left lurking and waiting for a new opportunity for a near miss to happen. For example, in one report dealing with a pilot ladder found to have one rubber step bent, the corrective action taken was to repair the step and fix the ladders. An additional corrective action was a requisition of new pilot ladders, but the reason why the rubber step was bent was never investigated. Another interesting near-miss report dealt with falls from height (fall overboard). It included pilot boarding, where one pilot was left unattended and the bridge team was unaware of him. The risk included fall from height, and the immediate corrective action in the report was "captain from bridge advised that second pilot is on gangway". An additional corrective action report was that the situation would be discussed during the next safety meeting onboard. However, it can be concluded that there was something wrong in the procedure (the bridge team was unaware that two pilots were boarding a ship), and the root cause was not addressed. In the correspondence between the tanker and the company, it was found that the DPA reacted and revised the procedure for pilot boarding, but it was not reflected in the filled-in near-miss report form. If the root cause is not addressed, adequate safeguards will not be in place to prevent near-miss recurrence or its development into a more serious incident.

Out of the analysed 309 reported near-miss events, only three reports produced changes to the company safety management system (pilot boarding policy was revised, a new checklist was issued for unmanned machinery spaces, and new equipment was installed in the cargo control room). However, changes were not recorded on near-miss reports as they were supposed to be, but it was reported separately via e-mails that changes were introduced due to investigation of the reported near-misses. Therefore, although it was a positive step towards safety improvements, the proper way would be to record it on near-miss reports, as there was an appropriate section.

The Chi-square test of independence evidenced the relationship between corrective action and near-miss risk level, and an interesting finding is that elimination and substitution as the two most effective corrective actions were associated with lower risk levels. In comparison, 
PPE was associated with higher risk levels. Therefore, it can be concluded that corrective actions for higher risk levels involved less effective controls, whereas corrective actions for lower risk levels involved more effective controls. The results obtained are in line with [31], where the authors also found that corrective action implementing safe work procedures is associated with higher-risk-level near-misses, whereas elimination and substitution are associated with lower-risk-level events. Another relationship found was between near-miss types and near-miss corrective actions, whereas specific corrective actions were associated with specific near-miss types. Although they are considered the least effective, implementing safe working practices and PPE are the most frequently implemented corrective actions. However, reported near-misses involving equipment failure included substitution and engineering as the most common corrective actions taken. Elimination was reported as frequent corrective action for the housekeeping near-miss type because it is relatively simple to remove the source of hazard in those lower-risk-level events.

The analysis confirmed a significant relationship between onboard locations where near misses occurred and risk levels. Although $64 \%$ of all reported near misses in our case study were associated with deck area, higher risk levels involving near misses occurred in the engine room and navigating bridge. These near-miss reports involved a relatively higher number of high- and critical-risk-level events, which could have caused significant damage or even fatalities. Several near misses associated with the navigating bridge included thirdparty violation, and corrective actions, for example, included only evasive manoeuvres to avoid collision followed by discussion of hazardous occurrence with the bridge team. Introducing new technologies on ships with the aim of improving safety might sometimes induce human error, such as complacency, error due to inadequate equipment design, or poor knowledge of own ship systems [49]. Adequate familiarisation, effective teamwork, and training improvements could be some of the preventive measures that need to be implemented onboard ships.

Data analysis showed that it is impossible to predict where events with more severe risk levels will occur. When analysed, the ship's position at the time of the near miss occurrence was not associated with near-miss risk levels. Therefore, it can be concluded that the severity of adverse events is not connected with the position of a ship, meaning that hazardous occurrences could happen anywhere and anytime. However, most of the recorded events occurred while the ship was at sea and anchored, such as in [12]. Therefore, each shipboard operation should be carefully planned and risk assessments and associated permits prepared to mitigate risks and develop a "healthy" safety culture onboard.

\section{Conclusions}

Near-miss reports are invaluable to safety improvements, as they enable learning without serious incidents. Nevertheless, a near-miss management system must be adequate and must function appropriately to enable such learning and improve safety onboard a ship. Review and analysis of near-miss reports in this case study revealed several significant findings:

- Most of the reported near-miss events occurred on deck, but the engine room and navigating bridge were the areas where a relatively larger number of higher-risk-level events occurred.

- Most of the reported near misses were related to housekeeping, equipment failure, use of PPE, and process/procedure related.

- $\quad$ Fall from height and lock out/tag out near-miss types were related to higher risk levels.

- Near-miss risk levels were associated with corrective actions. Moreover, lower risk levels were associated with more effective corrective actions, whereas higher risk levels were associated with less effective corrective actions.

- The ship's position at the time of the near-miss event was not related to the near-miss risk level.

- Analysis of the reports indicated that the section intended to be filled in by the office was never used (at least, reports were never received back from the office), which 
might be considered an undesirable practice. It might negatively affect reporting and act as a barrier because seafarers were not receiving feedback on appropriate forms.

- The prioritisation phase of the near-miss management system was not developed on a tanker ship. Due to a large number of reports, not all events could be investigated and analysed. Therefore, there is a need to estimate the risk level of reported near misses. With regard to the findings of this study, the following safety measures are suggested:

- Toolbox meeting topics and risk assessments should include findings of reported near-miss investigations and analyses.

- Adequate housekeeping should be ensured onboard by performing regular inspections and safety rounds.

- Safe behaviour, including adequate PPE usage and adherence to company procedures, should be promoted and instilled during additional safety training, monthly safety meetings, and the example set by shipboard leadership.

- If applicable, onboard processes and procedures should be changed and adapted according to the findings of the near-miss analyses.

- Adequate and regular maintenance of shipboard equipment as per the manufacturers' instructions and a shipboard planned maintenance system should be ensured. In addition, a sufficient number of spare parts should be kept onboard, and spare parts lists should be kept updated.

- More effective corrective actions for higher-risk-level events should be detected and implemented.

- Near-miss report forms should be adequately filled in, and crewmembers should be briefed on follow-up actions for each report.

- The prioritisation phase should be introduced in the near-miss system since it might expedite investigations of higher-risk-level events.

The limitations of this study are as follows:

- As mentioned in the Methodology section, it is a case study of a tanker ship. Therefore, it only reviews and analyses reports prepared on that ship and policies and procedures for one specific shipping company. Therefore, the findings of this study should be taken with caution. It cannot be concluded that all reported near-miss events in shipping have characteristics like the ones analysed in this study, and they can be somewhat different. For example, it can be expected that near-miss reports on a cruise ship will be different from reports on a tanker ship. Nevertheless, the authors' opinion is that this study's findings are relevant for the tanker industry since they point out issues that might guide future studies.

- A relatively small number of reported near-miss events might affect the study's findings. However, all reported near misses on one tanker ship were analysed in this study, and for future research, we will include more ships and more shipping companies to increase the sample size.

- The authors classified and estimated near-miss risk levels, which might be affected by subjectivity. Therefore, three authors who could be considered experts in the field performed the coding and risk assessment, and the external expert with significant experience in the tanker industry validated the results.

- Due to reporting barriers that might exist onboard a ship, it could be expected that not all near-miss events were recorded.

- $\quad$ Company policy regarding near-miss reporting consisted of one report each week. Hence, it might have negatively affected the reports' quality because crew members might have imagined a near-miss event and reported it as real in some cases. Unfortunately, the authors could not verify whether all reports were real. However, the intention of this study was not to verify or validate reported events, but to come to conclusions essential for improving safety at sea.

As this study does not deal with factors affecting the near-miss reporting system and its complexity, future studies will be pointed in that direction. In addition, the issue of near- 
miss report quotas will be studied because such requirements might motivate crewmembers to fabricate reports, affecting investigations and analysis. As a result, conclusions drawn from such reports might be inadequate and lead researchers astray, while real latent causes could be unrecognised and could continue producing adverse events in shipping. Finally, since a larger sample size is required to generalise findings and conclusions, future studies will aim to include different types of ships and shipping companies.

Author Contributions: Conceptualisation, N.H. and S.V.; methodology, N.H.; software, M.M.; validation, N.H., S.V. and M.K.; formal analysis, N.H.; investigation, N.H.; resources, N.H.; data curation, N.H.; writing - original draft preparation, N.H.; writing-review and editing, S.V., M.K. and M.M.; visualisation, N.H.; supervision, N.H. and S.V. All authors have read and agreed to the published version of the manuscript.

Funding: This research received no external funding.

Institutional Review Board Statement: Not applicable.

Informed Consent Statement: Not applicable.

Data Availability Statement: Near-miss data are available from the corresponding author on request.

Acknowledgments: The authors would like to express their gratitude to the tanker company for providing the near-miss reports and NMMS policy and to captain Dean Šlingar for his invaluable help during the risk assessments.

Conflicts of Interest: The authors declare no conflict of interest.

\section{References}

1. Dulebenets, M.A. A comprehensive multi-objective optimization model for the vessel scheduling problem in liner shipping. Int. J. Prod. Econ. 2018, 196, 293-318. [CrossRef]

2. United Nations Conference on Trade and Development (UNCTAD). Review of Maritime Transport. 2021. Available online: https:/ / unctad.org/system/files/official-document/rmt2021_en_0.pdf (accessed on 8 December 2021).

3. Pasha, J.; Dulebenets, M.A.; Kavoosi, M.; Abioye, O.F.; Theophilus, O.; Wang, H.; Kampmann, R.; Guo, W. Holistic tac-tical-level-planning in liner shipping: An exact optimization approach. J. Shipp. Trd. 2020, 5, 8. [CrossRef]

4. Pasha, J.; Dulebenets, M.A.; Fathollahi-Fard, A.M.; Tian, G.; Lau, Y.-Y.; Singh, P.; Liang, B. An integrated optimization method for tactical-level planning in liner shipping with heterogeneous ship fleet and environmental considerations. Adv. Eng. Inform. 2021, 48, 101299. [CrossRef]

5. Dui, H.; Zheng, X.; Wu, S. Resilience analysis of maritime transportation systems based on importance measures. Reliab. Eng. Syst. Saf. 2021, 209, 107461. [CrossRef]

6. The Economist. A Perfect Storm for Container Shipping. Available online: https://www.businessreview.global/latest/614d6a9e7 a15374d1a320f42 (accessed on 8 December 2021).

7. Marsh. Ever Given: A Catastrophic Incident or Near-Miss. Available online: https://www.marsh.com/uk/industries/marine/ insights / ever-given-a-catastrophic-incident-or-near-miss.html (accessed on 8 December 2021).

8. International Maritime Organization. MSC-MEPC.3/Circ.2, Casualty-Related Matters, Code of the International Standards and Recommended Practices for a Safety Investigation into a Marine Casualty or Marine Incident; International Maritime Organization: London, UK, 2008.

9. Hasanspahić, N.; Frančić, V.; Vujičić, S.; Maglić, L. Reporting as a Key Element of an Effective Near-Miss Management System in Shipping. Safety 2020, 6, 53. [CrossRef]

10. International Maritime Organization. Guidance on Near-Miss Reporting. MSC-MEPC.7/Circ.7. IMO. 4 Albert Embankment; International Maritime Organization: London, UK, 2008.

11. Zhou, Z.; Li, C.; Mi, C.; Qian, L. Exploring the Potential Use of Near-Miss Information to Improve Construction Safety Performance. Sustainability 2019, 11, 1264. [CrossRef]

12. Zhou, Q.; Wong, Y.D.; Loh, H.S.; Yuen, K.F. ANFIS model for assessing near-miss risk during tanker shipping voyages. Marit. Policy Manag. 2019, 46, 377-393. [CrossRef]

13. Bhattacharya, Y. Hazard and Near-Miss Reporting-Safety through Numbers? J. Marit. Res. 2019, 14, 33-42.

14. International Maritime Organization. ISM Code, International Safety Management Code and Guidelines on Implementation of the ISM Code; International Maritime Organization: London, UK, 2010.

15. Vepsalainen, A.; Lappalainen, J. Utilization of Incident Reporting in the Finnish Maritime Industry; Centre for Maritime Studies, University of Turku: Turku, Finland, 2010.

16. Probst, T.M.; Estrada, A.X. Accident under-reporting among employees: Testing the moderating influence of psychological safety climate and supervisor enforcement of safety practices. Accid. Anal. Prev. 2010, 42, 1438-1444. [CrossRef] [PubMed] 
17. Psarros, G.; Skjong, R.; Eide, M.S. Under-reporting of maritime accidents. Accid. Anal. Prev. 2010, 42, 619-625. [CrossRef]

18. Erdoğan, I. Best Practices in Near-Miss Reporting. Master's Thesis, Chalmers University of Technology, Goteborg, Sweden, 2011.

19. Oltedal, H.; McArthur, D. Reporting practices in merchant shipping, and the identification of influencing factors. Saf. Sci. 2011, 49, 331-338. [CrossRef]

20. Lappalainen, J.; Vepsäläinen, A.; Salmi, K.; Tapaninen, U. Incident reporting in Finnish shipping companies. WMU J. Marit. Aff. 2011, 10, 167-181. [CrossRef]

21. Storgård, J.; Erdoğan, I.; Lappalainen, J.; Tapaninen, U. Developing Incident and Near-miss Reporting in the Maritime Industry-A Case Study on the Baltic Sea. Procedia Soc. Behav. Sci. 2012, 48, 1010-1021. [CrossRef]

22. Georgoulis, G.; Nikitakos, N. The Importance of Reporting All the Occurred Near-misses on Board: The Seafarers' Per-ception. TransNav Int. J. Mar. Navig. Saf. Sea Transp. 2019, 13, 657-662. [CrossRef]

23. Hasanspahić, N.; Frančić, V.; Vujičić, S.; Maglić, L. Near-miss Reporting as Seen from Seafarers' Perspective. TransNav Int. J. Mar. Navig. Saf. Sea Transp. 2021, 15, 825-831. [CrossRef]

24. Bhattacharya, Y. Hazard and Near-Miss Reporting-An Analysis of the Effectiveness of Increased Error Reporting. Ternational. J. e-Navig. Marit. Econ. 2020, 15, 103-113.

25. Pedrosa, M.H.; Guedes, J.C.; Dias, I.; Salazar, A. New Approaches of Near-Miss Management in Industry: A Systematic Review. In Occupational and Environmental Safety and Health III. Studies in Systems, Decision and Control; Arezes, P.M., Baptista, J.S., Carneiro, P., Branco, J.C., Costa, N., Duarte, J., Guedes, J.C., Melo, R.B., Miguel, A.S., Perestrelo, G., Eds.; Springer: Cham, Germany, 2022; Volume 406. [CrossRef]

26. Awolusi, I.; Marks, E. Near-Miss Reporting to Enhance Safety in the Steel Industry. Iron Steel Technol. 2015, 2, 62-68.

27. Yang, K.; Ahn, C.R.; Vuran, M.C.; Aria, S.S. Semi-supervised near-miss fall detection for ironworkers with a wearable inertial measurement unit. Autom. Constr. 2016, 68, 194-202. [CrossRef]

28. Raviv, G.; Shapira, A. Systematic approach to crane-related near-miss analysis in the construction industry. Int. J. Constr. Manag. 2018, 18, 310-320. [CrossRef]

29. Vastveit, K.R.; Boin, A.; Njí, O. Learning from incidents: Practices at a Scandinavian refinery. Saf. Sci. 2015, 79, 80-87. [CrossRef]

30. Haas, E.J.; Yorio, P.L. The role of risk avoidance and locus of control in workers' near-miss experiences: Implications for improving safety management systems. J. Loss Prev. Process Ind. 2019, 59, 91-99. [CrossRef] [PubMed]

31. Haas, E.J.; Demich, B.; McGuire, J. learning from Workers' Near-miss Reports to Improve Organizational Management. Min. Metall. Explor. 2020, 37, 873-885. [CrossRef]

32. Chung, Y.-H.; Kim, D.J. Analysis on Management Status and Issues for Near-miss Reporting in Nuclear Power Industry. J. Korean Soc. Saf. 2016, 31, 177-186. [CrossRef]

33. Jones, S.; Kirchsteiger, C.; Bjerke, W. The importance of near-miss reporting to further improve safety performance. J. Loss Prev. Process. Ind. 1999, 12, 59-67. [CrossRef]

34. Alakiikonen, A. Developing Safety and Security in Organisations through Low Barrier Incident Information Management: A Case Study. Master's Thesis, Aalto University, Espoo, Finland, 2015.

35. Kohler, F. Barriers to Near-Miss Reporting in the Maritime Domain. Master's Thesis, Linköpings University, Linköping, Sweden, 2010

36. Phimister, J.R.; Oktem, U.; Kleindorfer, P.R.; Kunreuther, H. Near-Miss Incident Management in the Chemical Process Industry. Risk Anal. 2003, 23, 445-459. [CrossRef] [PubMed]

37. Wang, Z. The Use of Near-Misses in Maritime Safety Management. Master's Thesis, Dalian Maritime University, Dalian, China, 2006.

38. National Safety Council. Near-Miss Reporting Systems. Available online: www.nsc.org/WorkplaceTrainingDocuments/NearMiss-Reporting-Systems.pdf (accessed on 21 September 2021).

39. Subsea 7. Group Health, Safety, Environment and Security Handbook; MA-GL-HSE-005 Version 1; 2012. Available online: https:/ / docplayer.net/183821-Group-health-safety-environment-and-security-handbook-february-2012-ma-gl-hse-005version-1-seabed-to-surface.html (accessed on 21 September 2021).

40. Jacobsen, B. Near-Miss-Part of a Safety Culture. Seahealth Denmark. Available online: www.merikotka.fi/cafe/images/stories/ cafe/IMISS/bo_jacobsen.pdf (accessed on 22 September 2021).

41. Williamsen, M. Near-Miss Reporting: The Missing Link in Safety Culture. Prof. Saf. 2013, 58, 46-50.

42. Gnoni, M.G.; Saleh, J.H. Near-miss management systems and observability-in-depth: Handling safety incidents and ac-cident precursors in light of safety principles. Saf. Sci. 2017, 91, 154-167. [CrossRef]

43. Margaryan, A.; Littlejohn, A.; Stanton, N.A. Research and development agenda for Learning from Incidents. Saf. Sci. 2017, 99, 5-13. [CrossRef]

44. International Maritime Organization. Revised Guidelines for Formal Safety Assessment (FSA) for Use in the IMO Rule-Making Process. MSC-MEPC.2/Circ.12/Rev.2. IMO; International Maritime Organization: London, UK, 2018.

45. Workplace Safety and Health Council. Code of Practice on Workplace Safety and Health (WSH) Risk Management. WSHCouncil, 2nd Revision. Available online: https://www.tal.sg/wshc/-/media/TAL/Wshc/Resources/Publications/Codes-of-Practice/ Files/CodeOfPractice_RiskManagement_SecondRevision.pdf (accessed on 10 October 2021).

46. Manuele, F.A. Risk Assessment \& Hierarchies of Control. Their growing importance to the SH\&E profession. Saf. Manag. 2005, 50, 33-39.

47. McLeod, S.; Curtis, C. Integrating urban road safety and sustainable transportation policy through the hierarchy of hazard controls. Int. J. Sustain. Transp. 2020, 1-15. [CrossRef] 
48. McHugh, M.L. The Chi-square test of independence. Biochem. Med. 2013, 23, 143-149. [CrossRef] [PubMed]

49. Bielić, T.; Hasanspahić, N.; Čulin, J. Preventing marine accidents caused by technology-induced human error. Sci. J. Marit. Res. 2017, 31, 33-37. 